\title{
Kidh Fabric: Product Development for Community Business Reinforcement
}

\author{
Watcharin Sriburin ${ }^{1}$, Natthaphong Phudlar ${ }^{1} \&$ Aongthong Boonserm ${ }^{1}$ \\ ${ }^{1}$ The Faculty of Cultural Science, Mahasarakham University, Khamriang Sub-District, Kantarawichai District, \\ Maha Sarakham Province 44150, Thailand \\ Correspondence: Watcharin Sriburin, The Faculty of Cultural Science, Mahasarakham University, Khamriang \\ Sub-District, Kantarawichai District, Maha Sarakham Province 44150, Thailand. E-mail: \\ wsriburin154@outlook.com
}

Received: June 27, 2015 Accepted: July 13, 2014 Online Published: September 22, 2014

doi:10.5539/ach.v7n1p111 URL: http://dx.doi.org/10.5539/ach.v7n1p111

\begin{abstract}
This research, Kidh fabric: product development for community business reinforcement was conducted with three main aims: 1) to study Kidh fabric history in northeastern Thailand; 2) to study problems and solutions related to processed fabric products; and 3) to study fabric product pattern design development for community business reinforcement. This qualitative study used a purposive random sampling technique, with samples including people involved with Tai Dam fabric products. Data were collected through structured interview, observation, focus group discussion and work shop.In addition, data reliability and validation tests were conducted with a triangulation method. The results show that Kidh Fabric production processes from three community business groups had the same points in keeping their unique designs and purposes to improve their own business and marketing. There needs to be coordination between community members in the production and design processes, as well as to increase product value by using new knowledge and technology. In conclusion, to develop Kidh fabric products for community reinforcement, all three communities need more support and cooperation from government units, private organization and community leaders. Moreover, these communities businesses need more knowledge and technological support to improve their production process, marketing, personalities in order to transform their community production units into strong and stable business groups.
\end{abstract}

Keywords:Kidh fabric, product development, community business, Northeastern Thailand

\section{Introduction}

Kidh fabric is one of the unique community products of northeastern Thailand, which requires special art techniques to create. This kind of art has been passed continuously from one generation to the next. Kidh fabric line patterns are created from personal technique and individual creativity and are woven onto fabric sheets. They reveal the traditions and wisdom of local people (Leesuwan, 1981)

Kidh fabric weaving used to be extensively known and used in northeastern Thailand. These days it seems to be less popular, even if cultural academics and developers have tried hard to support and promote Kidh fabric use, production and marketing. The researchers' opinion is that Kidh fabric still lacks support from both government units and private organizations in knowledge, technology and application.

\section{Research Methodology}

This research, Kidh fabric: product development for community business reinforcement was conducted with three main aims: 1) to study Kidh fabric history in northeastern Thailand; 2) to study problems and solutions related to processed fabric products; and 3) to study fabric product pattern design development for community business reinforcement. The investigation used a qualitative research method to study the background and present conditions of northeastern Thai communities and the Kidh fabric weaving process and traditions. A development method was used to study the development and application of Kidh fabric production networks for community business reinforcement. The researchers collected data form research, documents and field study by means of observation, interview, group discussion and workshop. The study began in October 2013 and lasted until February 2014. The sample included people involved in Kidh fabric in northeastern communities of Thailand, spanning 3 provinces: UdonThani, Nongbualamphoo and Loei by using a purposive random sampling 
technique to create homogenous groups, these were: 34 key informants, 68 casual informants and 36 general informants. Data reliability and validation tests were conducted using a triangulation method and analyzed by content analysis, field notes and descriptive analysis.

\section{Results}

\subsection{Background of KidhFabric in Northeastern Thailand}

Baan Na Ka, Mueang District, UdonThani Province is a famous source of Kidh fabric production located in the north of UdonThani province. Mhee-Kidh or Kidh fabric weaving has been a community business supported by the office of UdonThani community development since 1957. Baan KhudHae, Na Klang District, Nongbualamphoo Province is the biggest Kidh silk production source in Nongbualamphoo Province. KhudHaeKidh silk is delicately crafted and the techniques used to create the fabric have been passed from one generation to the next. The most fabulous product is the Kidh pillow, which is made from 40 different patterns of Kidh silk. 'Thai-Loei local fabric' is the local product of Baan Kang Pla community business group, located in Tam boom Chaiyapruek, Mueang District, Loei province. Weaving is their traditional business, since the local industrial resource is cotton. The Kang Pla fabric identity is silver and gold thread patterns.

\subsection{Problems and Solutions Related to Processed Fabric Products for Community Business}

The production process of $\mathrm{Na} \mathrm{Ka}$ fabric at Baan $\mathrm{Na} \mathrm{Ka}$, Mueang District, UdonThani Province is less complicated, faster and more varied than in the past. Moreover, the fabric can be transformed to make various products, for example clothes and household goods, due to the more varied patterns and colors.However, the community business group faces fabric pattern imitation problems that need to be solved as soon as possible by patent registration.

The KhudHae community weaving business group of Na Klang District, Nongbualamphoo Province focuses on producing the most distinguished woven kidh silk, which leads to the improvement of working capital. The products can be applied to various uses. Nevertheless, the community business group needs to improve the stability of product color, since the fabric preparation still uses traditional processes and natural dyes.

The community business group of Baan Kang Pla, Mueang District, Loei Provincehas improved its production process to be easier and faster. Additionally, their product variation and patterns have improved. Regardless, the community faces product imitation problems and a lack of production technology. These problems need time, cooperation and creativity to solve.

\subsection{Fabric Product Pattern Design Development for Community Business Reinforcement}

The researchers found that all three local communities have improved and applied their fabric patterns and products to be more suitable, stylish and unique in order to add product value. The communities have cooperated with funding and brainstorming in order to develop their products to meet the needs of the market and are more acceptable. Table 1 highlights the specific details of Fabric product pattern design development for community business reinforcement.

Table 1.Fabric product pattern design development for community business reinforcement

\section{Production}

1.Quantity of products: Sufficient for the market and community demand, could be reproduced and increased to meet the market and consumer demand.

2 Pattern, quality and added value: Improved product uniqueness and patterns to suit the needs of the market. Fabric quality, color stability and patterns retained.

3. Production networks: Development of production networks to work together in groups, creation of a consultation group to improve productivity, quality and standards. Establishment of a network to develop knowledge and share ideas.

\section{Funding}

1. Government funding support: The community received funding through the million fund bank loans from the bank of Agriculture and Cooperation and other banks.

2. Private organization: Stores and related companies promote budgets for pattern designs and increase the standard of Kidh fabric production. 
3. Community funding: Funding from community members contributes to a strong community business group.

\section{Personality}

1. Community guru: There are combinations of old and new concepts, but they are incomplete because there are many external factors involved.

2. Production network: The community groups branched out to do their own individual work and then finally put their work together as a production network to create a quality community identity of Kidh fabric products.

3. Relative group: Weaving Kidh is a system of participation between family members and groups of relatives.

\section{Marketing}

1. Community network: Cooperation between community members builds stronger bargaining power in the market and brings more support from external organizations.

2. External business network: External business groups provide flexibility in the operation of all sectors, especially with trade and investment.

\section{Conclusion}

Bann $\mathrm{Na} \mathrm{Ka}$ is a huge production and distribution source of Kidh fabric in UdonThani, since there are local weaving groups that traditionally weave Kidh fabric using local knowledge, maintaining $\mathrm{Na} \mathrm{Ka}$ fabric identity and improving products to meet consumer demand. Woven Kidh silk of the KhudHae community is a traditional craftsmanship that came from local wisdom and has been passed down since ancient times. The first local people weaved Kidh fabric to use it to sew Kidh pillows but after the establishment of Kidh weaving groups, the community business groups started weaving for sale and sewing clothes. 'Thai Loei local fabric' is a traditional craft, which utilizes beautiful patterns created by the traditional knowledge of Kang Pla locals. The fabric is made from pure cotton, with lace inserted to add value.

The production of $\mathrm{Na}$ Ka Kidh fabric has been improved to be more expedient and prompt. Production has expanded to accommodate a larger marketfor both fabric and clothes. Moreover, the community business groups have improved the products to be more varied, colorful and stylish. The Kidh woven silk products of KhudHae are very unique and fabulous. Every piece of fabric produced increases profit. Kidh woven silk tends to be developed in terms of quality and according to a set of standards. The issue with production is that fiber preparation still lacks stability in quality, color and patterns. Kang Pla Kidh fabric in present day Loei Province has been improved to be more unique, since the community businesses focus on maintaining identity and quality, in addition to product development. The main problem encountered by community businesses is the instability of the community groups, due to unequal support within the community and from external organizations. Application of Kidh fabric to create new patterns and add value to the products has been improved from simple and undistinguished ideas to clearer, more beautiful and more unique designs.

\section{Discussion}

The development of Kidh fabric products for community business reinforcement in Baan Na Ka, Baan KhudHae and Baan Kang Pla needs more support from both government and non-government organizations. Moreover, it depends on the community leaders of each group to have methods and new ideas to lead the production process development, fabric design and quality improvement. According to the researchers' opinion, the three community business groups need to improve the processes involving fabric production, so that production meets market demand in terms of design, quality, value and identity. Production and marketing networks must be created both inside and outside of the community. There must be additional funding support from the bank of Agricultural and cooperation, SML funds, non-government organization funds and community funds.

In conclusion, to develop Kidh fabric products for community reinforcement, all three communities need more support and cooperation from government units, private organization and community leaders. Moreover, these communities businesses need more knowledge and technological support to improve their production process, marketing, personalities in order to transform their community production units into strong and stable business groups. Elements of rural business management divide management into production management, marketing management, funding management, people management and general management. The key area of management is the process of planning, organizing and directing manpower and controlling performance. Besides, the proportions of work will depend on the size of company. The community businesses have the same goals, which are profits, growth and expansion, while continuing to increase their business value. 


\section{Suggestions}

\subsection{Practical Implementation of the Research Results}

- The results of this investigation can be used to develop the northeastern community economies.

- The application of Kidh fabric weaving wisdom should be promoted as an example of community development to other communities across Thailand.

- Government organizations involved with community development should provide knowledge support such as seminars, conferences and workshops in order to promote community business improvement.

- Research journals could provide knowledge about applications of silk production for Northeastern community economic development.

\subsection{Suggestions for Further Research}

- Further research should concern the application of Kidh fabric impact on economic development.

- There should be a parallel study of the development of Kidh Fabric products between different communities in the same district or province to find models of economic development and Kidh fabric product applications using remaining indigenous knowledge.

- The application of local wisdom of Kidh fabric weaving should be studied to develop northeastern community businesses and promote the importance of traditional Kidh weaving, including ceremonial culture and traditions connected with Kidh fabric.

- The application of Kidh fabric local knowledge should be studied to develop of community economies in northeastern Thailand and preserve traditional local fabric.

\section{References}

Andoh, N. K. (1999). The impact of structural adjustment on regional interaction in Sub-Saharan Africa: African community economic development. Harvard: Harvard University.

Certo, S. C. (1989). Principles of modern management. Massachusetts: Allyn and Bacon.

De Barcza, G. M. A. (1988). Art heritage perpetuation in contemporary Fijian culture.PhD Thesis, University of Georgia.

Dozier, D. S. W. (2000).Kumeyaay basketry: Resource management as an economic strategy. PhD Thesis, University of California.

Fair, S. W. (1994). Native art in the public eye: The affirmation of tradition [Alaska]. PhD Thesis, University of Pennsylvania.

Fernandez, P. L. (2006). Government policy towards community economic development in Manitoba. Manitoba: University of Manitoba.

Kanno, T. (1997).An institutional analysis of the commercial viability of two weaving projects in Northeastern Thailand.KhonKaen: KhonKaen University.

Leesuwan, W. (1981).Thai cultural heritage [in Thai]. Bangkok: Office of the National Culture Commission, Ministry of Education.

Lehman, M. A. (1994). The life and work of contemporary professional potters. New York: McGraw Hill.

Mathewson, M. S. (1998). The living web: Contemporary expressions of Californian Indian basketry. $\mathrm{PhD}$ Thesis.University of California, Berkeley.

Moore, C. L. W. (1999). A social and economic impact analysis of community business development: Leather finishing in a small town. Texas: Texas Tech University.

Preissing, J. (2006). Community economic development strategic planning for rural communities: A case study of successful programs. Minnesota: University of Minnesota.

Rosengarten, D. (1997). Social origins of the African-American low-country basket.PhD Thesis.Harvard,Harvard University.

\section{Copyrights}

Copyright for this article is retained by the author(s), with first publication rights granted to the journal.

This is an open-access article distributed under the terms and conditions of the Creative Commons Attribution license (http://creativecommons.org/licenses/by/3.0/). 